\title{
Advanced Glycation End Products and Acute Myocardial Infarction
}

\author{
Peter Celec ${ }^{a, b}$ Stella Burskáe Katarína Šebekovác Marta Kalousová ${ }^{f}$ \\ Tomáš Zima ${ }^{f}$ Ján Murín ${ }^{d}$ \\ ${ }^{a}$ Institute of Pathophysiology, Faculty of Medicine, ${ }^{b}$ Department of Molecular Biology, Faculty of Natural Sciences, \\ Comenius University, ${ }^{C}$ Institute of Preventive and Clinical Medicine, Slovak Health University, and ${ }^{\mathrm{d}}$ 1st Department of

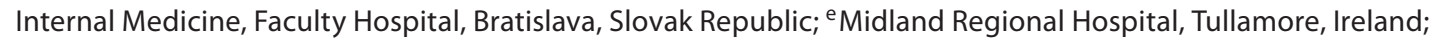 \\ ${ }^{f}$ Institute of Clinical Biochemistry and Laboratory Diagnostics, 1st Faculty of Medicine, Charles University, \\ Prague, Czech Republic
}

\section{Key Words}

Advanced glycation end products · Carbonyl stress ·

Acute myocardial infarction

\begin{abstract}
Objective: The aim of this study was to analyse the dynamics of advanced glycation end products (AGEs) after acute myocardial infarction (MI). Subjects and Methods: Blood samples were taken from 20 non-diabetic patients with acute MI on the 1st, 2nd, 3rd and 5th day after the onset of symptoms. Serum AGE levels were estimated spectrofluorometrically. Results: A marked decrease in the AGE-specific fluorescence was observed, especially between the 1st and the 2nd days after MI. Conclusion: The findings of this study tend to contradict the suggestion that AGEs are relatively stable markers of carbonyl stress. Although the reason for this is currently unknown, this observation may have implications for ongoing studies of AGEs in cardiovascular diseases.
\end{abstract}

Copyright $\odot 2010$ S. Karger AG, Basel
(C) 2010 S. Karger AG, Basel

1011-7571/10/0193-0244\$26.00/0

Fax +4161306 1234

E-Mail karger@karger.ch

www.karger.com
Accessible online at: www.karger.com/mpp

\section{Introduction}

Advanced glycation end products (AGEs) are related to the development of complications in diabetic patients. AGEs are produced by non-enzymatic reactions between proteins and carbonyl compounds like e.g. sugars, especially during hyperglycaemia [1]. However, other factors like oxidative stress, renal failure and aging can also produce higher serum levels of AGEs. Although AGEs became an important area of research in diabetology in the last decade, this group of substances, also called glycotoxins or melanoidins, has been long known in food industry and in nutrition research, as they are consumed in large amounts in different kinds of cooked food [2].

AGEs were considered important pathophysiological substances, and their levels were found to be elevated in diabetes mellitus and also in Alzheimer disease, nephropathy and atherosclerosis [3]. Evidence for the presence of depositions of the specific AGE product $\mathrm{N}(\varepsilon)$ (carboxymethyl)lysine in intra-myocardial blood vessels of patients with myocardial infarction (MI) indicates the importance of AGEs in cardiovascular pathophysiology [4]. AGE-specific fluorescence is a marker of carbonyl stress that covers all fluorescent AGEs. Although not specific, this marker has been used widely [5]. 
Intra-individual variations in serum AGE levels are thought to be very small and the changes caused by chronic illness such as diabetes last for months or years [6]. However, under specific conditions that include renal failure, AGE concentration has been shown to double during a period of only $24 \mathrm{~h}$ [7]. This fact led us to investigate whether or not AGE levels change during acute events like MI and if so whether it has any significance.

\section{Subjects and Methods}

Twenty non-diabetic patients (7 females and 13 males, aged $60-75$ years) with a primary diagnosis of MI were enrolled in the study. The diagnosis was confirmed by S-T elevation, as well as biochemical and clinical parameters. Patients underwent standard therapeutic procedures and were not classified by clinical parameters. Informed consent was obtained from the patients. Blood samples $(3 \mathrm{ml})$ were withdrawn from each patient into a test tube on days 1-5 after the onset of the symptoms. The blood was left to stand for $30 \mathrm{~min}$ and was then centrifuged at 3,000 rpm to separate serum.

Serum AGE levels were estimated spectrofluorometrically $\left(\lambda_{\mathrm{ex}}=350 \mathrm{~nm}, \lambda_{\mathrm{em}}=450 \mathrm{~nm}\right)$ expressed as arbitrary units (AU) on a Synergy 2 spectrofluorometer (Tecan, Austria). Interassay and intra-assay coefficients of variation are 5-6 and 4-7\%, respectively.

\section{Results}

The results show (fig. 1) a decrease in the AGE-specific fluorescence especially between the 1st and the 2 nd day after MI by $18 \%$, from $277.9 \pm 46.9$ to $233.4 \pm 28.4$ AU ( $\mathrm{p}<0.005)$. The decrease continued further (by $25 \%)$ to $213.7 \pm 32.2 \mathrm{AU}$ on day 5 ( $\mathrm{p}<0.001)$. This progressive reduction of AGE-related fluorescence from day 1 to days 2 and 5 was statistically significant $(\mathrm{p}=$ 0.005). The basal values from the time before the onset of symptoms or after full recovery from the attack were not measured. Although AGE fluorescence is measured in arbitrary units and, thus, cannot be compared between laboratories, normal values range between 150 and $250 \mathrm{AU}$.

\section{Discussion}

The findings of this study tend to contradict the suggestion that AGEs are a relatively stable marker of carbonyl stress. Dynamic changes of plasma AGEs within days have not been described in patients previously. In the absence of pre-MI AGE levels, what happened to these

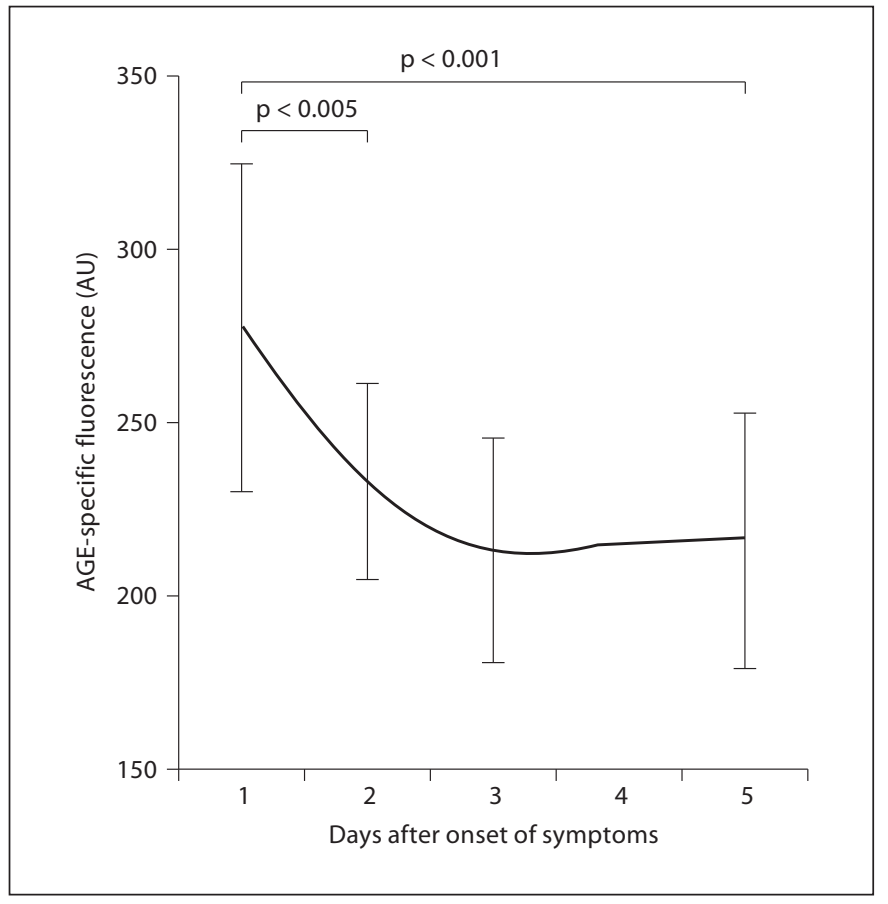

Fig. 1. Serum AGE-specific fluorescence in 20 patients during the first 5 days after MI (means \pm standard deviation).

substances in the first $24 \mathrm{~h}$ following MI cannot be ascertained from this study. Age and gender were not associated with AGE levels in this study, probably due to the small number of patients and a large interindividual variability. The observed dynamics of post-MI changes in AGE fluorescence can be explained by various mechanisms. Exogenous factors like pharmacological interventions, for example thrombolytic therapy, fraxiparin and aspirin may cause such a change, but none of the standard therapeutic agents used here is known to affect AGEs. Changes in the production of AGEs by various tissues including heart and vessels and/or their renal elimination of AGEs are, therefore, more likely to cause the decrease.

The AGE receptor called RAGE activates nuclear factor $\kappa \mathrm{B}$. AGEs induce pathological changes in different tissues at the subcellular level by activating this transcription factor. This pathway is similar to the mechanism of action of free radicals, $\beta$-amyloid and other cytotoxic molecules. Experimental studies have shown that RAGE activation by AGEs is an important modulator of the ischaemia-reperfusion injury of the heart [8] and brain [9]. In this context, an interesting possibility would be to reduce the cytotoxic effect with the so-called AGE breakers. 


\section{Conclusion}

A significant decrease in the serum AGE-specific fluorescence was found in patients during the first 5 days after acute MI. In further studies including normal subjects matched for patients, reconvalescence values are warranted to evaluate the present findings and their significance.

\section{Acknowledgments}

The authors are grateful to the BiomeD Research and Publishing Group and to the Children's Hope Club. The work was supported by a grant of the Agency for Support of Science and Research LPP-0133-06 and by governmental grants VEGA 1/4316/07, VEGA 1/0307/08 and 2006/24-UK-03.

\section{References}

1 Brownlee M, Cerami A, Vlassara H: Advanced glycation end products in tissue and the biochemical basis of diabetic complications. New Engl J Med 1988;318:1315-1321.

2 Somoza V: Five years of research on health risks and benefits of Maillard reaction products: an update. Mol Nutr Food Res 2005;49: 663-672.

3 Ahmed N: Advanced glycation endproducts - role in pathology of diabetic complications. Diabetes Res Clin Pract 2005;67:3-21.

4 Baidoshvili A, Krijnen PA, Kupreishvili K, Ciurana C, Bleeker W, Nijmeijer R, Visser CA, Visser FC, Meijer CJ, Stooker W, Eijsman L, van Hinsbergh VW, Hack CE, Niessen HW, Schalkwijk CG: N(epsilon)(carboxymethyl)lysine depositions in intra- myocardial blood vessels in human and rat acute myocardial infarction: a predictor or reflection ofinfarction? Arterioscler Thromb Vasc Biol 2006;26:2497-2503.

5 Munch G, Keis R, Wessels A, Riederer P, Bahner U, Heidland A, Niwa T, Lemke HD, Schinzel R: Determination of advanced glycation end products in serum by fluorescence spectroscopy and competitive ELISA. Eur J Clin Chem Clin Biochem 1997;35:669677.

6 Wolffenbuttel BH, Giordano D, Founds HW, Bucala R: Long-term assessment of glucose control by haemoglobin-AGE measurement. Lancet 1996;347:513-515.

-7 Boor P, Bozek P, Blazicek P, Syrova D, Schinzel R, Heidland A, Pecovova A, Se- bekova K: Increased levels of circulating advanced glycation end products in a model of acute renal insufficiency in rats. Cas Lek Cesk 2001;140:375-380.

8 Bucciarelli LG, Kaneko M, Ananthakrishnan R, Harja E, Lee LK, Hwang YC, Lerner S, Bakr S, Li Q, Lu Y, Song F, Qu W, Gomez T, Zou YS, Yan SF, Schmidt AM, Ramasamy R: Receptor for advanced-glycation end products - key modulator of myocardial ischemic injury. Circulation 2006;113:1226-1234.

9 Hassid BG, Nair MN, Ducruet AF, Otten ML, Komotar RJ, Pinsky DJ, Schmidt AM, Yan SF, Connolly ES: Neuronal RAGE expression modulates severity of injury following transient focal cerebral ischemia. J Clin Neurosci 2009;16:302-306. 